\title{
The public health response to the COVID-19 outbreak in mainland China: a narrative review
}

\author{
Mark Zanin ${ }^{1,2,3}$, Cheng Xiao ${ }^{1}$, Tingting Liang ${ }^{1}$, Shiman Ling ${ }^{1}$, Fengming Zhao ${ }^{1}$, Zhenting Huang ${ }^{1}$, \\ Fangmei Lin ${ }^{1}$, Xia Lin ${ }^{1}$, Zhanpeng Jiang ${ }^{1}$, Sook-San Wong ${ }^{1,2,3} \wedge$ \\ ${ }^{1}$ State-Key Laboratory of Respiratory Diseases, Guangzhou Medical University, Guangzhou, China; ${ }^{2}$ Guangzhou Institute of Respiratory Health, \\ Guangzhou, China; ${ }^{3}$ School of Public Health, The University of Hong Kong, Hong Kong, China \\ Contributions: (I) Conception and design: M Zanin, SS Wong; (II) Administrative support: M Zanin, SS Wong; (III) Provision of study materials \\ or patients: None; (IV) Collection and assembly of data: C Xiao, T Liang, S Ling, F Zhao, Z Huang, F Lin, X Lin, Z Jiang; (V) Data analysis and \\ interpretation: All authors; (VI) Manuscript writing: All authors; (VII) Final approval of manuscript: All authors. \\ Correspondence to: Sook-San Wong. Professor, State Key Laboratory of Respiratory Diseases, 195 Dongfengxi Rd., Guangzhou, China. \\ Email: Sook-San.Wong@GIRD.cn.
}

\begin{abstract}
The COVID-19 pandemic caused by the severe acute respiratory syndrome coronavirus 2 (SARS-CoV-2) has caused nations to adopt unprecedented control measures in order to curb its spread. As the first nation to respond, China's aggressive control measures appeared to have been effective in suppressing the first wave and keeping new cases under control. Here, we provide the historical context and details of China's public health response to COVID-19. We highlight the lessons and impact of the 2002-2003 SARS outbreak, which demonstrated the importance of transparency, surveillance and testing laboratories during an outbreak. We provide an overview of China's response strategy that was based on the principles of early detection, isolation, management and treatment and involved not only the largescale coordination of multiple governmental bodies but also grass-root community participation throughout the country. These community-based organizations conducted active surveillance for febrile cases and provided support for those in quarantine and communities in lockdown. Importantly, these broader measures were supported by digital technology, including the extensive use of internet-based platforms and mobile applications (APPs). While there have been no significant increases in case numbers since April, there is still much concern over a second wave, considering the resumption of work and school, the lifting of travel restrictions and the outbreaks occurring globally. Control measures has since been implemented by provincial authorities, which includes continued surveillance and rapid testing. Although China's strict control measures may not suit every nation, the principles of early detection and isolation continue to hold true and have been a cornerstone of the initial and ongoing response to the COVID-19.
\end{abstract}

Keywords: Severe acute respiratory syndrome coronavirus 2 (SARS-CoV-2); COVID-19; pandemic; coronavirus; public health

Submitted Jun 14, 2020. Accepted for publication Jul 26, 2020.

doi: $10.21037 /$ jtd-20-2363

View this article at: http://dx.doi.org/10.21037/jtd-20-2363

\footnotetext{
$\wedge$ ORCID: 0000-0002-1290-191X.
} 


\section{Introduction}

\section{The COVID-19 outbreak in mainland China}

On December 31, 2019 the Wuhan Health Commission announced a cluster of 27 cases of atypical pneumonia. These cases were initially linked to the Huanan Seafood Market, which was closed and sanitized the following day (1). On January 8 the China Centers for Disease Control and Prevention (China CDC) officially announced the causative agent to be a novel coronavirus closely related to bat coronaviruses (2-4). Initial public health responses, concentrated in Wuhan, became a national emergency when cases were reported beyond Wuhan and human-to-human transmission was confirmed in a family cluster in Shenzhen, Guangdong province (5) (Figure 1).

On January 16, the China CDC upgraded the emergency response to level I, the highest level (Table 1). On January 20 the novel coronavirus was classified as a Category B pathogen, making it a legal requirement to immediately report cases. The lockdown of Wuhan was announced in the early morning of January 23, barring all citizens from leaving without special permission after $10 \mathrm{am}$. By this time cases had been reported in all provinces except Tibet. Complicating matter was chunyun, the Spring Festival travel season that is considered to be the largest human migration event globally (6). In 2020, the Spring Festival was slated to begin on January 25, and millions of residents had already left Wuhan prior to the lockdown (7).

Between December 31, 2019 and March 22, 2020, considered the first COVID-19 wave, China recorded 80,695 confirmed cases (Figure 2A), 67,707 of which is in Hubei Province (Figure 2B). Wuhan alone recorded 49,912 cases (Figure 2C). The burden of the epidemic in China was borne primarily by Hubei Province, which accounted for $83 \%$ of its' cases. Wuhan alone accounted for $62 \%$ of the national tally. Close to 700,000 close contacts were traced or monitored by the end of March (8). Between March 8 to June 12 2020, China has recorded only an additional 3,976 cases, 1,808 (45\%) of these cases were diagnosed as imported cases (9).

The goal of this review is to provide a cohesive overview of the response during the first wave of COVID-19 between December 2019 and April 2020 and to put this response into a historical context, namely the 2003 severe acute respiratory syndrome coronavirus (SARS-CoV) outbreak. Further, the greater national response has mostly been overshadowed by Wuhan's lockdown, which was considered unprecedented in the early days. Our review attempts to provide a (I) broader perspective of the public health measures taken across mainland China, which was guided in a top-down approach and (II) highlighting the underappreciated but critical roles of grass-root communities and digital technology in this response.

We present the following article in accordance with the Narrative Review reporting checklist (Available at http:// dx.doi.org/10.21037/jtd-20-2363).

\section{Methods}

\section{Search strategy and selection criteria}

Data for this review published in English or Chinese were identified by searches of PubMed, Chinese State, Provincial, Municipal and local government authorities' websites and the national or local news outlets published between December 1, 2019 to June 1, 2020. All articles in Chinese were first translated by software and manually reviewed by our bilingual team members.

\section{The National Surveillance and Public Health System in China in the post-SARS era}

In the last 30 years, China has dealt with several viral epidemics of zoonotic origin (Table 2). The human to human transmissibility of SARS-CoV that emerged in 2002 however, proved to be a significant test of China's public health system and was catalytic for its reform $(14,15)$. The early events of the SARS outbreak presented valuable learning opportunities for outbreak control $(16,17)$. Interventions and control measures were put in place and mandatory quarantine for suspected or confirmed cases of SARS was introduced, as was epidemiologic tracing of close contacts, whom were also required to undergo home quarantine (18). Collective quarantine at designated facilities was also introduced (19). Guangdong province implemented a meticulous contact tracing system that included a questionnaire to be completed within 24 hours of reporting (20). Fever clinics were established, designated SARS hospitals were opened and public places were closed for several weeks (19). Guangdong, Hong Kong and Beijing were the hardest hit. At the end of 2003, 8,096 cases had been reported worldwide, 774 of which were fatal (13).

Three key lessons were taken away from SARS: (I) the importance of transparency to ensure social stability, (II) the importance of disease surveillance, and, (III) the importance of testing laboratories. These elements formed the basis of the 'Five Es': "Early Detection", "Early 


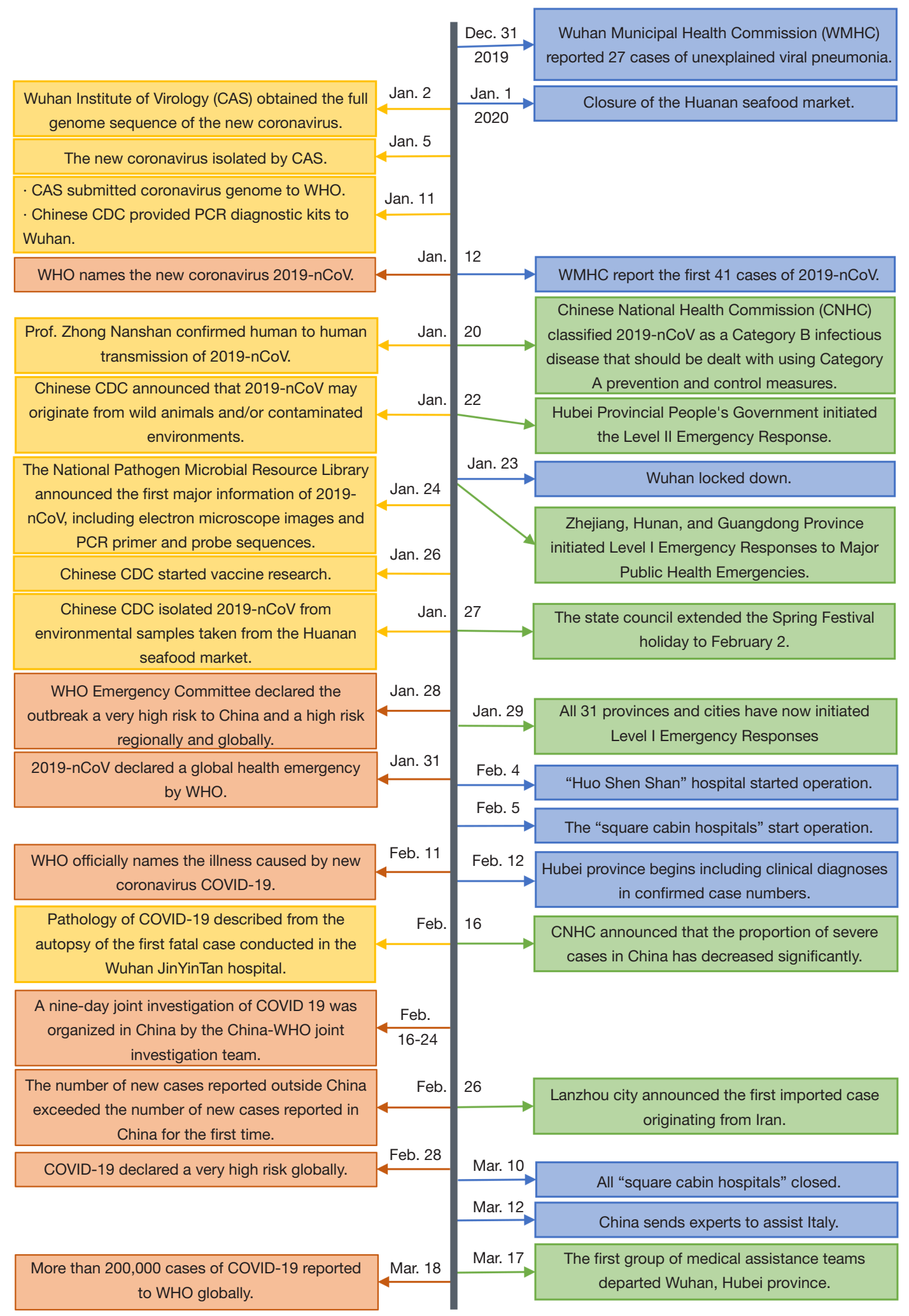

Figure 1 Timeline of major events in mainland China of the COVID-19 outbreak from December 2019 to March 2020. Blue, events in Wuhan; green, events in mainland China; yellow, research progress; red, announcements by the WHO. 
Table 1 Structure of the public health emergency response levels of China

\begin{tabular}{ll}
\hline Level & Authorization \\
\hline I & Extremely serious public health emergency \\
Coordinated at the State Council level & Serious public health emergency \\
Coordinated at the provincial level with guidance from \\
the State Council if required \\
Public health emergency \\
Coordinated at the municipal level with guidance from \\
the Provincial Health Commission if required \\
General public health emergency \\
Coordinated at the district level with guidance from the \\
Municipal Health Commission if required
\end{tabular}

Notification", "Early Diagnosis", "Early Isolation" and "Early Treatment" (16). The government began to invest substantially in public health infrastructure by increasing funds, resources and the sizes of skilled workforces $(14,15)$. To enable rapid reporting and monitoring, the Ministry of Health implemented the internet-based disease reporting system; the China Information System for Disease Control and Prevention (CISDCP). The CISDCP supports the real-time reporting of cases, a significant advantage over the previous reporting system requiring hospitals to submit case-report forms to local CDCs which then submitted monthly reports up the chain to the national CDC. The CISDCP is utilized in the national surveillance system established to detect emerging pathogens by the Chinese Ministry of Health under the "National Implementation Plan

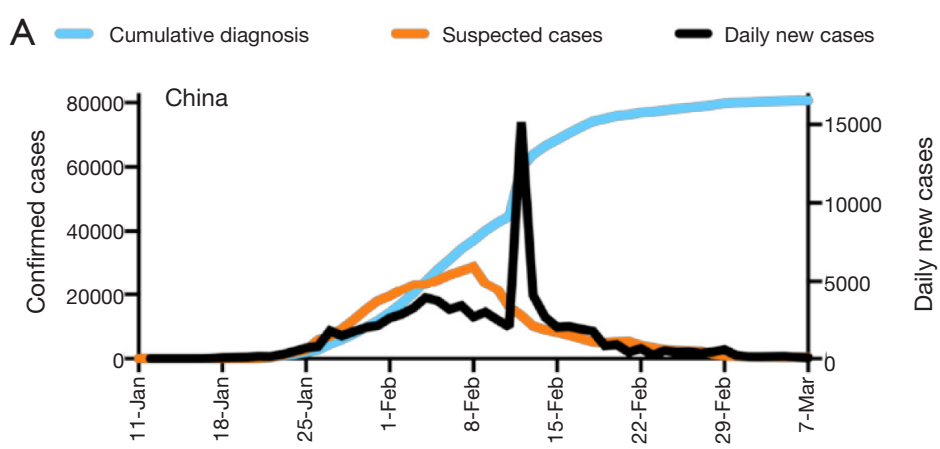

B

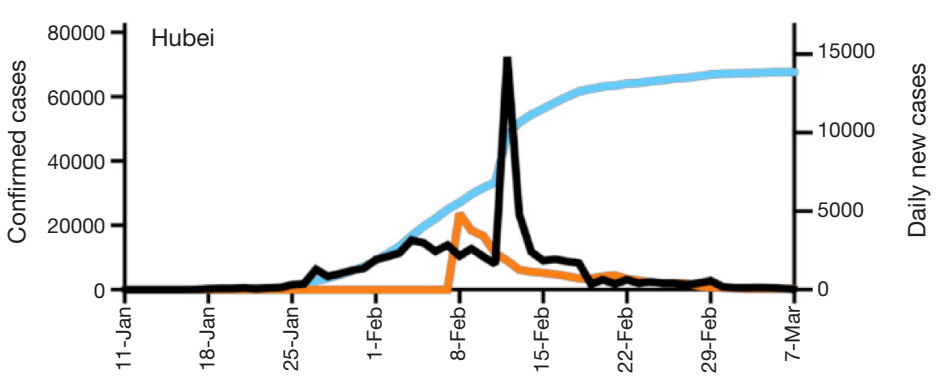

C

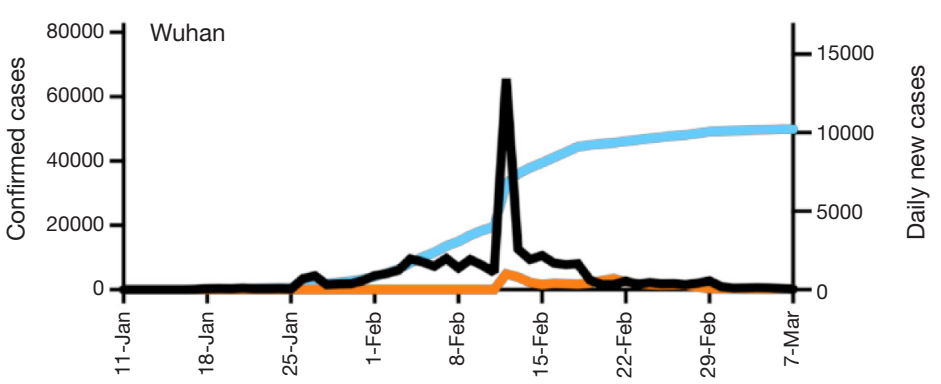

Figure 2 Progression of the COVID-19 outbreak in mainland China. Epidemic trends of confirmed, suspected and new daily cases in China (A), Hubei Province (B) and Wuhan (C) between 11 January 2020 and 7 March 2020. 
Table 2 Epidemics of significant public health concern in China in the last 30 years

\begin{tabular}{|c|c|c|c|c|c|}
\hline Pathogen & Outbreak duration & Peak activity & Epicenter & Number of cases & Fatal cases \\
\hline Avian influenza H7N9 (12) & $2003-2020$ & $04 / 2013$ & Zhejiang & 1,568 (2013-2019) & 616 \\
\hline SARS (13) & 02/2013-2019 & $02 / 2003$ & Guangdong \& Beijing & 5,327 (2002-2003) & 349 \\
\hline SARS-CoV-2 (8) & 2013-2019 & $02 / 2020$ & Wuhan & $81,202^{\mathrm{a}}$ & 3,242 \\
\hline
\end{tabular}

${ }^{\mathrm{a}}$, Number of cases in China as of 18 March, 2020.

for Surveillance of Unexplained Pneumonia", announced on August 4, 2004 (21) (Figure 3).

\section{China's COVID-19 epidemic control and prevention program}

The four elements considered critical to China's response were: (I) the lockdown of Wuhan, (II) the implementation of interagency mechanisms to control the epidemic outside of Wuhan, (III) the reporting of daily cases and zero cases (no cases detected) by all cities and provinces of China, and (IV) the implementation of community level surveillance and support system. Recognizing the importance of interagency communication and coordination, the National Health Committee (NHC) led the formation of the State joint prevention and control mechanism on January 20. This mechanism involved a total of 32 ministries or departments forming various working groups that focused on different aspects including epidemic prevention and control, treatment, research, publicity, foreign affairs, and logistical support (22). To ensure transparency to the public, the NHC coordinated the collection and publication of the daily tally of new and zero cases across the nation beginning on January 21. Finally, fearing that mass migration will lead to uncontrolled spread, the high-level expert group recommended locking down Wuhan. January 23 marked the date on which control measures were implemented nationwide to contain the spread (23). A coordinated topdown prevention and control program was implemented by the NHC and China CDC through a nine-point plan (24) (Table 3). Provincial and county level heath authorities then released guidelines to be enacted by various entities such as companies, institutions and neighborhood committees.

The severity of the outbreak led the NHC to adopt a different strategy in Wuhan and surrounding cities. The government mobilized resources to increase testing by fast-tracking approval for diagnostic kits, recruiting thirdparty diagnostic companies to build additional laboratory capacity, facilitating supply chains and making more isolation facilities available. In a well-publicized example, Wuhan built two new infectious disease hospitals in 10 days to manage severe cases. A number of 'square cabin hospitals' were also established in Wuhan to treat mild cases, which operated between February 5 and March 10, treating over 12,000 cases with a combined staff of more than 8,000 (25). Medical teams nationwide were mobilized to staff these new facilities and support the strained workforce in Wuhan (26). As of March 8, a total of 346 civilian medical teams consisting of 42,600 staff and more than 4,000 military medical personnel were deployed to Hubei Province $(8,27)$ (Supplementary file).

A critical aspect of early detection in Wuhan was active surveillance for febrile cases at the community level. On February 6, Wuhan implemented a city-wide temperature monitoring program to identify suspected cases. Using the community grid as the basic unit, working teams comprising of staff and volunteers were formed. A combination of onsite inspection and self-reporting was adopted. Citizens could perform temperature checks at home and self-report the results by phone or through the social media application (APP) WeChat. The working teams also saw to the needs and difficulties of the homebound residents (28).

To minimize domestic spread, the national Spring Festival holiday was extended for three days, interprovincial road travel and tour activities were banned and border control and surveillance for febrile persons were enacted $(29,30)$. Outside of Hubei Province, health authorities were directed to identify individuals coming from highrisks areas, track close contacts and rapidly isolate suspected cases (31). Inter-city measures to increase social distancing were implemented, including movement restrictions, the closure of public spaces, banning of mass gatherings and postponement of school start dates (Table 4). A total of 2,091 hospitals and 11,655 fever clinics were established across China for rapid detection and isolation of suspected cases (Figure 4). To increase testing and detection capacities 


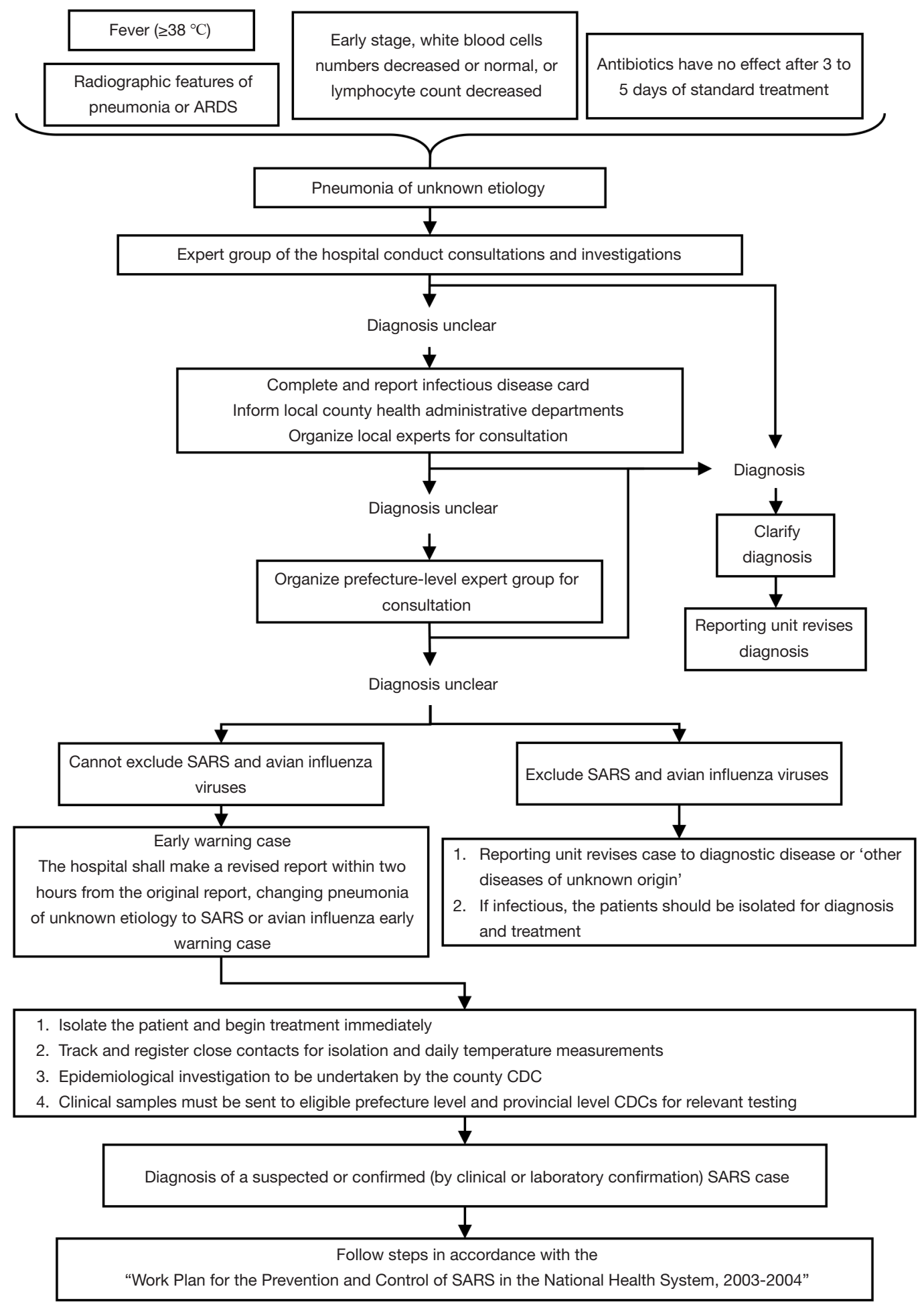

Figure 3 Flowchart of steps in diagnosing a 'pneumonia of unknown etiology' (PUE). Published in the 'National Implementation Plan for Surveillance of Unexplained Pneumonia', announced August 42004 by the Chinese Ministry of Health (21). 
Table 3 Summary of the nine-point plan introduced by the NHC and China CDC to combat the COVID-19 outbreak (24)

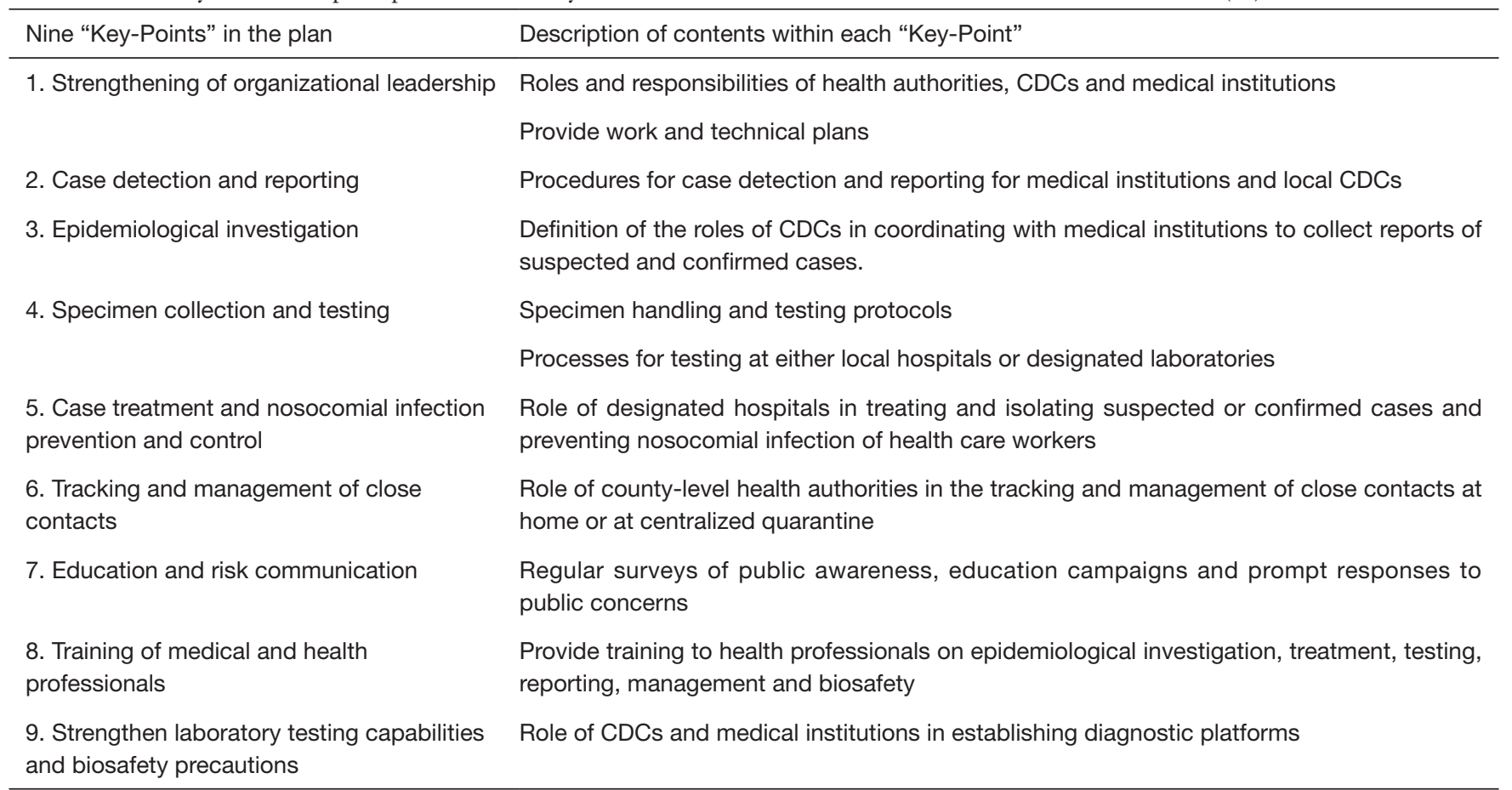

nationwide, local CDCs trained the laboratory staff of designated hospitals to perform diagnostic tests, reducing the reliance on a centralized testing $(52,53)$.

Although a uniformed response framework based on national guidelines was introduced, regional and local measures varied. For example, Guangzhou and Shenzhen, two first-tier cities in Southern China, implemented movement restrictions in residential areas (54). Shenzhen imposed a 14-day quarantine or rapid evacuation of entire residential buildings in which confirmed cases were identified (55). Several provinces also made the use of face masks mandatory in public places in the early days before this rule was eventually implemented nationwide. $(56,57)$. Purchases of fever or cough medication over the counter in pharmacies in Beijing and Guangdong must be registered, whilst in other cities sale of these medications were suspended (58). People requiring these medications were instructed to visit a hospital as soon as possible (58). In some cities, restrictions were placed on the number of household members allowed to leave home. These measures effectively cancelled Spring Festival celebrations and greatly reduced migration and mobility (Figure 5).

Closed off management of residential and commercial areas was implemented nationwide, from villages to large cities, to enable surveillance and temperature monitoring (54).
Citizen volunteers were recruited to man monitoring stations, conduct door-to-door health checks, monitor those in self-quarantine and enforce social distancing measures (59). Intensive public education and awareness efforts were established to promote hand-washing, health monitoring, social distancing and disinfection. Temperature scanning was enacted to identify and prohibit entry of suspected febrile individuals into public spaces (60). These measures were implemented by local anti-epidemic committees and replicated at multiple organizational levels nationwide.

In summary, China's epidemic control was coordinated from top-down but the participation at the grass-root community level ensured the critical citizen's compliance and the implementation of its program.

\section{The role of technology in the COVID-19 response}

In the last decade, China has undergone rapid growth in the digital technology sector (61). In the work plan of January 27, the State Council urged local authorities to utilize big data and other technologies to facilitate disease tracking $(62,63)$ (Figure 6). As inter-city or inter-province travel by train or air requires a valid Chinese ID or passport, the movements of confirmed COVID-19 cases could be traced. Telecom operators also participated, submitting daily tele 
Table 4 Summary of intervention policies enacted in mainland China in response to COVID-19

\section{National policies (29,32-39) \\ Extended the Official Spring Festival holiday to February 3 \\ Postponed school openings}

Banned all mass celebrations and activities

Cancellation of tours organized by travel agencies

Suspended inter-provincial buses between most the provinces

Banned the illegal sale of wild animals

Monitoring of body temperature in public places such as railway stations, airports, hospitals and supermarkets

Established various online services to assist people in staying home, such as online classes, banking services and medical and psychological consultations

Registration of people whom have traveled from Hubei Province to allow follow-up health monitoring, facilitating early discovery, early reporting and early quarantine

Tracing the travel of all close contacts of confirmed patients and imposing a 14-day quarantine

Mandatory use of facemasks in supermarkets and shopping malls

Additional provincial policies (40-50)

\section{Hubei Province}

Public transportation halted and population outflow from Wuhan and other cities in Hubei is limited

Building or refitting projects to establish makeshift hospitals and quarantined areas

Allowed clinical diagnosis as a method to diagnose cases

\section{Guangdong}

People visiting fever clinics must provide a naso-pharyngeal swab for nucleic acid testing

Guangdong, Zhejiang \& Beijing

People must register their information when buying antipyretics and cough medicines

Guangdong, Beijing \& Liaoning

Mandatory use of facemasks in public places

Shenzhen, Hainan \& Liaoning

Buildings with confirmed cases are subject to mandatory quarantine

Numerous provinces and cities

Non-native residents must register for a Health Code upon arrival data reports to track population mobility dynamically, and internet giants such as Alibaba, Tencent and Baidu were encouraged to share the geographical locations of users (64). Some provinces and municipalities used this dataset to establish publicly-accessible web-based platforms providing de-identified details of confirmed cases, including disease course, exposure history and movements. As NHC requires the nationwide tally of daily new confirmed, suspected, recovered and fatal cases available to the public, internet search engines like Baidu made these data searchable down to the city level and linked them to other relevant data, including latest news updates and migration data (9).

Other online services have also been established to help those under quarantine. Hospitals utilized online outpatient platforms to assist individuals using videobased consultations with doctors (32). QR code-based 'Health Codes' that can be displayed on mobile phones were also introduced. Health Codes are based on a 14-day history of daily self-reported health declarations, travel and exposure history and knowledge of local epidemic prevention information. They are required to gain access to public amenities, closed-off areas or to return to work. Based on the individual's response, the generated codes are divided into green, yellow and red. Green means pass, while yellow and red mean isolation and treatment (Figure 6E). This model was initially introduced in Hangzhou City on February 11. By March 5, one billion Tencent Health Codes, which are the Health Codes with the most users, were issued to more than 800 million people (65), although its intercity or interprovince usage is still limited to cities or provinces that have established prior mutual agreements.

Temperature monitoring has been an important component of the public health response. Large scale, automated infrared thermal scanning was implemented in airports, subway, and train stations while hand-held temperature sensors are used at other locations, such as buses, taxis restaurants and residential complexes (66). Some larger locations also employed facial recognition technology, allowing the identification of potentially febrile individuals. The rollout of the $5 \mathrm{G}$ network, which has come into service on a limited scale in hospitals and railway stations initially in Guangdong, Guangxi and Zhejiang Provinces, has facilitated these measures (67-69).

\section{A problem of scale}

The rapid spread of COVID-19 within Hubei Province 

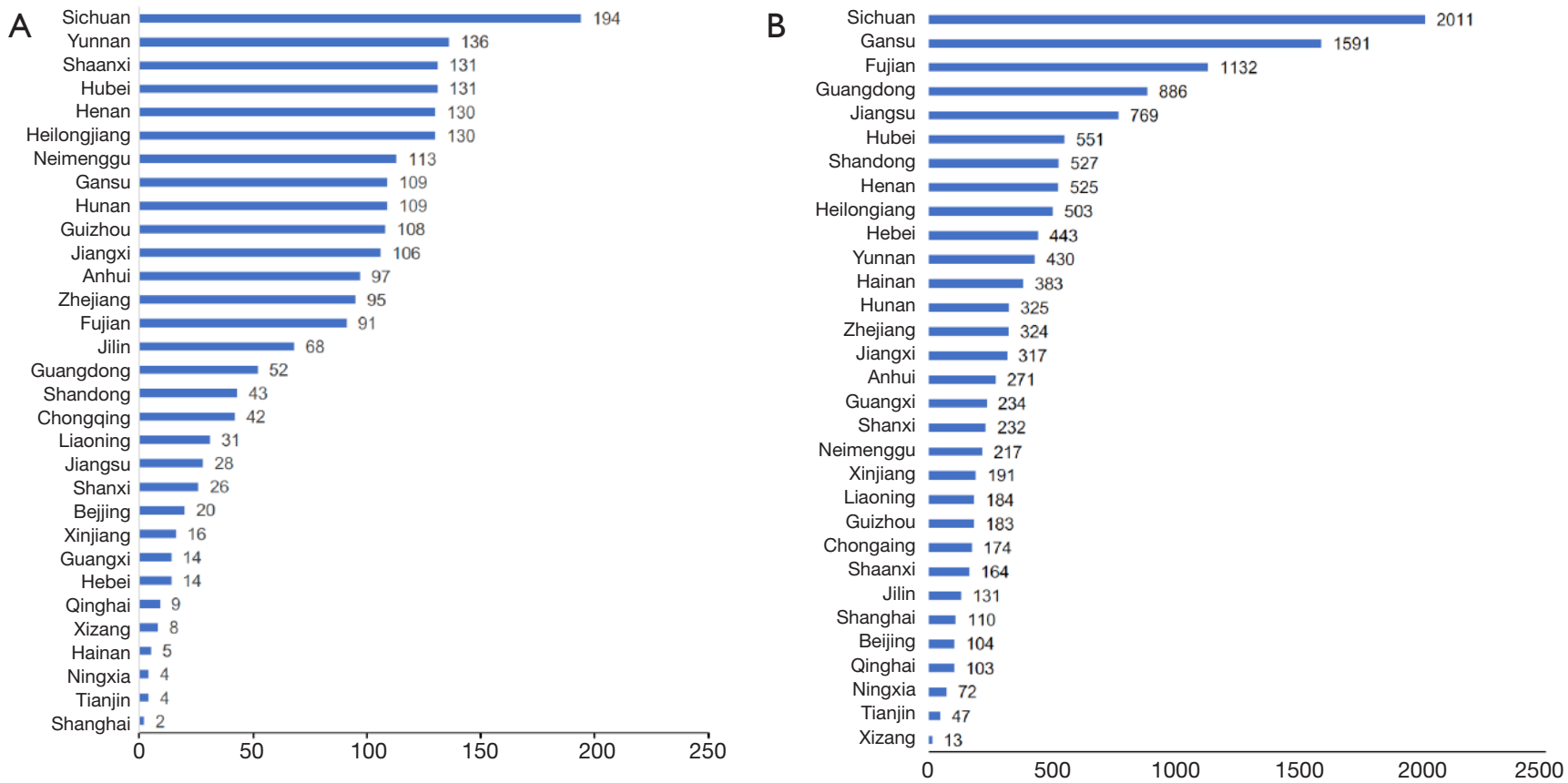

Figure 4 Distribution of hospitals and fever clinics in mainland China. Number of (A) designated hospitals, and (B) fever clinics across all provinces in mainland China (51).

rapidly overwhelmed diagnostic and healthcare capacities. Diagnostic kits based on real-time PCR methods were quickly deployed to Hubei Province by January 16, but the testing capacity was far from the capacity needed to diagnose the thousands of suspected daily cases (70). PCR testing delays created a bottleneck in case confirmation, which was necessary to access treatment. Therefore, the Hubei government revised case-confirmation criteria to include clinical diagnoses, leading to the addition of $>14,000$ cases overnight on February 13 (71). This measure allowed medical staff at the point-of-care to enact treatment and isolation measures more rapidly than previously possible.

The A-like classification of SARS-CoV-2 as a Category A agent meant that all health care workers at risk of exposure must don level-3 PPE, consisting of a full-protection suit, respirator, eye-protection and multiple gloves. This, along with the mandatory use of face masks by the public, placed significant strain on manufacturing and supply chains. Severe shortages in hospital beds, particularly in Wuhan, was also a major problem. The strain on medical resources was likely a contributing factor to the case-fatality rates (CFRs) observed in Wuhan and Hubei, at 4.9\% and 3.1\%, respectively, compared to $0.16 \%$ elsewhere in China before
February 4 (72).

\section{The known unknowns}

The 2-month long epidemic in China provided some critical information about this virus. A study of over 72,000 cases showed that the majority of infections ( $81 \%$ ) were mild, with an unadjusted CFR of $2.3 \%$, with the elderly and those with underlying conditions most at risk $(3,73)$. This CFR should be considered in the context of active detection, isolation and treatment. For provinces aside from Hubei, where medical facilities were well-prepared for the epidemic, the CFR were less than $1 \%$. The CFR reported across the different countries globally also reflected the importance of population demography and preparedness of medical resources.

Although the median incubation time has been reported to be 4 days, latency periods of more than 20 days had also been observed (73). There are also some reports of relapse, whereby patients deemed negative tested positive again (74). Reports have suggested that this phenomenon could be in as many as $14 \%$ of discharged patients (75), although the transmission potential of such 


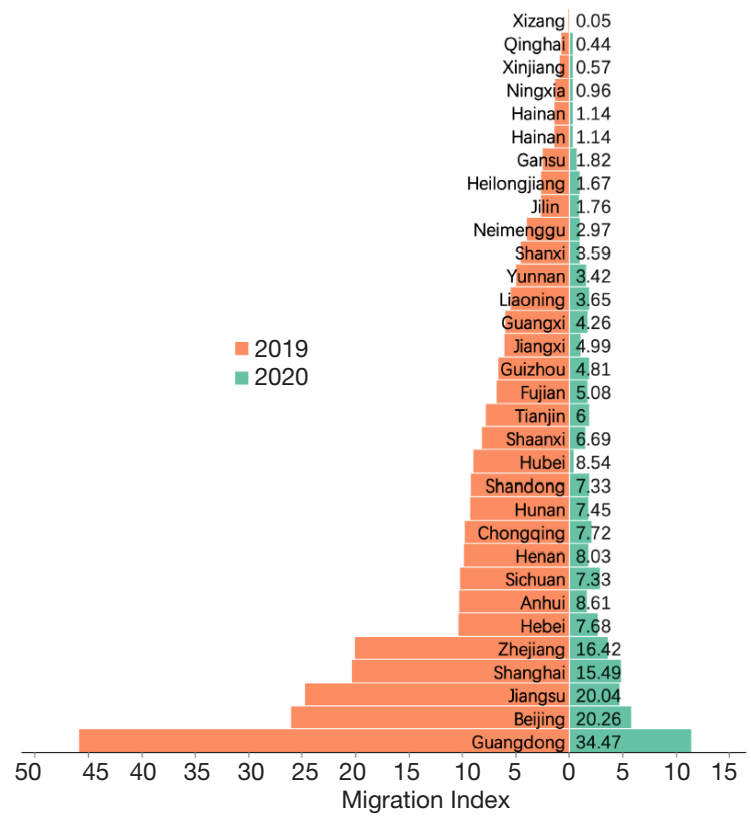

Figure 5 Effect of travel restrictions on chunyun migration patterns in mainland China. Migration indices for the 2019 (orange) and 2020 (green) on the 7th day of the Spring Festival, typically the peak of migration, in different provinces in mainland China. Values show the difference in migration index in each province between 2019 and 2020. Migration index based on the daily number of inbound and outbound events by rail, air and road traffic, were sourced from a web-based program: Baidu qianxi (in Chinese) (https://qianxi.baidu.com/).

cases are unknown. Infectious viruses have also been recovered in stool and urine specimens and up to $50 \%$ of cases have detectable viral RNA in their excretions (76). Fecal shedding has also been detected in asymptomatic cases (77). Therefore, unlike SARS, where most cases developed symptomatic infections rapidly, SARS-CoV-2 could manifest a diverse range of outcomes. Long latency, asymptomatic or mildly symptomatic infections increases the difficulty of identifying cases.

\section{A second wave?}

With the reduction of local transmission, local governments are slowly allowing businesses and people to return. Restrictions in Hubei Province, but not Wuhan, were lifted on March 25, but citizens are still required to wear masks and have normal body temperatures in order to leave (78). Large cities like Shanghai and Guangzhou downgraded their public health response to level II on March 24 and February 24, respectively $(79,80)$. The Wuhan lockdown was lifted on April 8, although residents must still apply for permission to leave (81). Schools, which has been closed since the Spring Festival, have mostly reopened by June 8th.

A major challenge in China now is to prevent subsequent waves, which includes preventing imported cases from seeding local transmissions. Health declarations, PCR screening and mandatory quarantines for all incoming passengers, regardless of nationality, have been introduced at China's major entry points (82). The Chinese Civil Aviation Authority has imposed stringent restrictions on air travel to and from China. Up to June 2020, these regulations restricted domestic airlines to one route to any country and one flight per week on these routes while foreign airlines were restricted to one route to China and no more than one flight per week on these routes. More recently however, they have introduced the "circuit breaker" policy, where airlines are penalized if substantial number of positive cases were detected on any one flight and rewarded if no positive cases were detected consecutively for 2 weeks (83). Further, foreign nationals holding visas or residence permits are temporarily suspended from entering China since 28 March 2020 (84). These travel restrictions have enabled early detection of imported cases and likely prevented the resurgence of local cases.

Domestically, the resumption of work and school have been accompanied by aggressive testing, increased sanitations, hygiene and health monitoring and implementation of social distancing measures. Gatherings are still largely prohibited. Large institutions such as universities are encouraged to adopt practices that reduce crowding by staggering school periods and meal times. Measures such as temperature scans, sanitation stations, facemasks and health codes remain in place (85). The monitoring systems and responses are now largely coordinated by local health authorities at the provincial or county level, who will continue to conduct epidemiological investigations and activate cordon sanitaire when upon detection of positive cases.

\section{Conclusions}

What has distinguished COVID-19 from previous outbreaks has been the scale and speed by which this contagion had spread, facilitated by its infectivity and the global connectivity. There was rapid progress in pathogen 


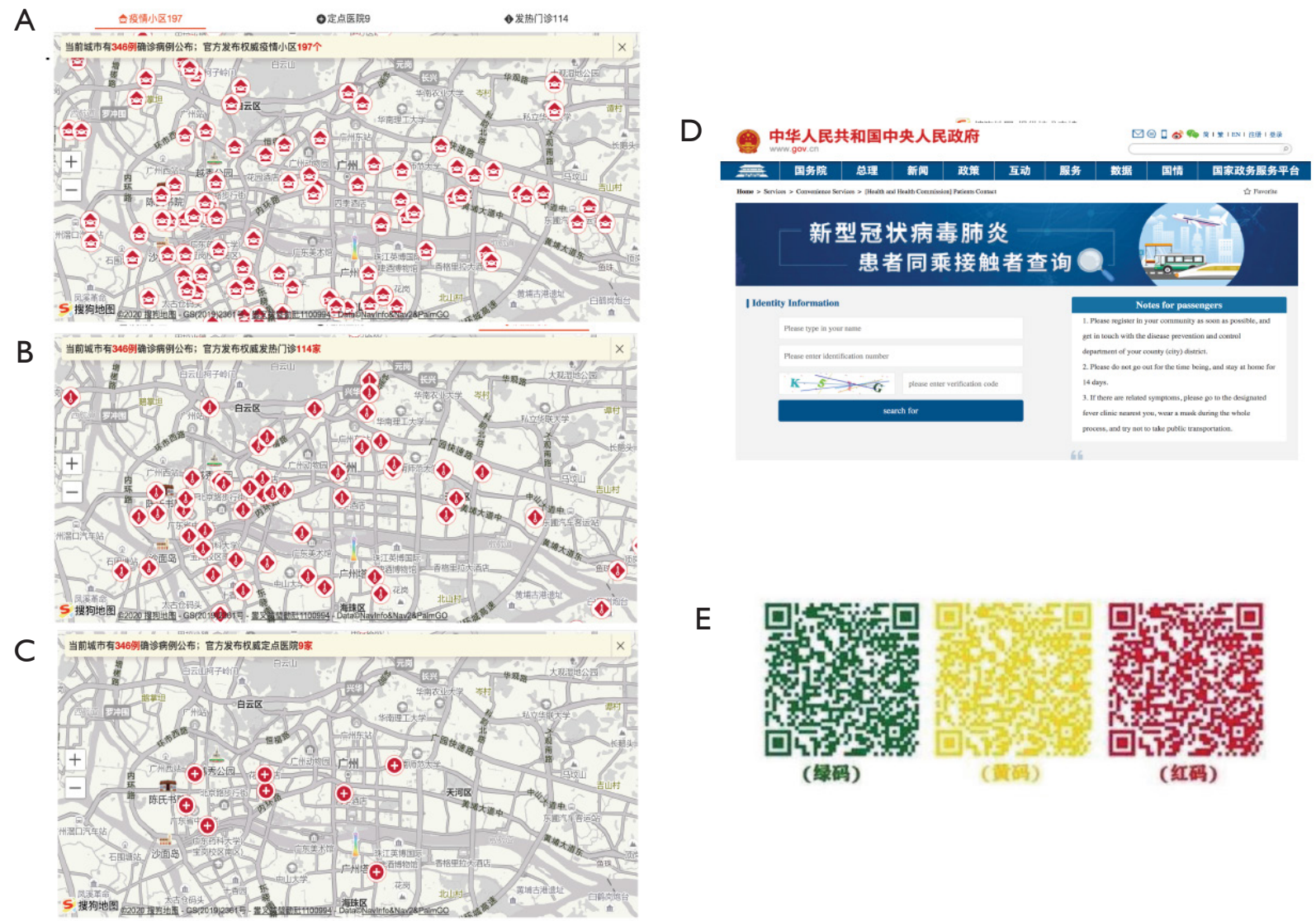

Figure 6 Examples of online tools for public use during the outbreak. Screenshots showing websites that provided searchable locations of (A) confirmed cases, (B) designated hospitals and (C) fever clinics available in Guangzhou city; (D) screenshot of an online portal provided by the National Health Commission to track potential exposure to confirmed cases based on public transportation usage; (E) example of the colored coded QR codes to signify health status for passage permission. Green means healthy with no associated risks, yellow means applicant is either recorded as a close contact, did not disclose their health status or had not yet completed 14-day home isolation, while red indicates that the applicant was either a confirmed or suspected case or febrile.

identification and development of diagnostic tests aided by technological development, but this advantage was soon diminished when the outbreak escalated and testing capacities became limited (86).

The economic consequences of a mass lockdown in China was substantial across many sectors, particularly in more traditional consumer-based industries. The service, investment, retail and export sectors fell by $13 \%, 24.5 \%$, $20.5 \%$, and $15.9 \%$, respectively, compared to the same period last year. Unemployment rate increased by $0.9 \%$ between January to February 2020. Although substantial, the negative economic impact was likely buffered by the Spring Festival for some industries and the growth of others, such as the digital economy (87).
We have attempted to provide a cohesive, but not necessarily exhaustive, review of China's response to COVID-19. In order to streamline our review, we have primarily focused on China's response to the first COVID-19 wave, which essentially set the foundation of their ongoing control efforts. China's efforts appeared to have successfully controlled local transmissions of the first COVID-19 wave but it had taken massive coordination at every level of governmental and civilian authorities. China had the benefit of experience, gained during the 2003 SARS epidemic, and citizen compliance was a critical factor to the success of the control measures implemented. Internetbased platforms and mobile APPs were used extensively for the first time in an epidemic to facilitate large-scale, real- 
time risk communication. These newer technologies were applied concurrently with the ancient countermeasures of isolation and quarantine. Going forward, further understanding of the virus's biology and transmission pattern will enable the implementation of a targeted, and less disruptive public health response. The principles of early detection and isolation continue to hold true and have been a cornerstone of the initial and ongoing response to the COVID-19 outbreak in China.

\section{Acknowledgments}

We thank Professor Nanshan Zhong of the State Key Laboratory of Respiratory Diseases, China, for his insights. We gratefully acknowledge Professor Benjamin Cowling of The School of Public Health, The University of Hong Kong, Professor Emeritus Dr. Robert Webster of St. Jude Children's Research Hospital, USA, and, Dr. Min Kang of the Guangdong Centers for Disease Control and Prevention for their insights and critical review of our manuscript. We thank Ms. Suiyan Chen for her help in preparing this manuscript.

Funding: SSW and MZ are supported by High-Level Talent Construction Plan of Guangzhou Medical University.

\section{Footnote}

Reporting Checklist: The authors have completed the Narrative Review reporting checklist. Available at http:// dx.doi.org/10.21037/jtd-20-2363

Conflicts of Interest: All authors have completed the ICMJE uniform disclosure form (available at http://dx.doi. org/10.21037/jtd-20-2363). The authors have no conflicts of interest to declare.

Ethical Statement: The authors are accountable for all aspects of the work in ensuring that questions related to the accuracy or integrity of any part of the work are appropriately investigated and resolved.

Open Access Statement: This is an Open Access article distributed in accordance with the Creative Commons Attribution-NonCommercial-NoDerivs 4.0 International License (CC BY-NC-ND 4.0), which permits the noncommercial replication and distribution of the article with the strict proviso that no changes or edits are made and the original work is properly cited (including links to both the formal publication through the relevant DOI and the license). See: https://creativecommons.org/licenses/by-nc-nd/4.0/.

\section{References}

1. Wuhan Municipal Health Commission. Wuhan Municipal Health Commission briefing on the current pneumonia epidemic situation in our city. 2019. Available online: http://wjw.hubei.gov.cn/fbjd/dtyw/201912/ t20191231_1822343.shtml

2. Ren LL, Wang YM, Wu ZQ, et al. Identification of a novel coronavirus causing severe pneumonia in human: a descriptive study. Chin Med J (Engl) 2020;133:1015-24.

3. The Novel Coronavirus Pneumonia Emergency Response Epidemiology Team. The epidemiological characteristics of an outbreak of 2019 novel coronavirus diseases (COVID-19)—China, 2020. China CDC Weekly 2020;2:113-22.

4. Zhou P, Yang XL, Wang XG, et al. A pneumonia outbreak associated with a new coronavirus of probable bat origin. Nature 2020;579:270-3.

5. Yu P, Zhu J, Zhang Z, et al. A familial cluster of infection associated with the 2019 novel coronavirus indicating possible person-to-person transmission during the incubation period. J Infect Dis 2020;221:1757-61.

6. McCarthy N. Chinese New Year: the world's largest human migration is about to begin. 2018. Available online: https://www.forbes.com/sites/niallmccarthy/2018/02/14/ chinese-new-year-the-worlds-largest-human-migration-isabout-to-begin-infographic/\#29e019be124d

7. Zhao S, Zhuang Z, Ran J, et al. The association between domestic train transportation and novel coronavirus (2019-nCoV) outbreak in China from 2019 to 2020: a data-driven correlational report. Travel Med Infect Dis 2020;33:101568.

8. The Central Committee of the Communist Party of China and the State Council of China. Press Conference of the Joint Prevention and Control Mechanism of the State Council. 2020. Available online: http://www.gov.cn/ xinwen/gwylflkjz67/index.htm

9. Baidu. Epidemic real-time big data report. Available online: https://voice.baidu.com/act/newpneumonia/ newpneumonia/?from=osari_pc_1

10. World Health Organization. Cumulative number of confirmed human cases of avian influenza $\mathrm{A}(\mathrm{H} 5 \mathrm{~N} 1)$ reported to WHO. 2020. Available online: https://www. who.int/influenza/human_animal_interface/H5N1_ 
cumulative_table_archives/en/

11. World Health Organization. H5N1 highly pathogenic avian influenza: Timeline of major events. 2014. Available online: https://www.who.int/influenza/human_animal_ interface/H5N1_avian_influenza_update20141204. pdf?ua $=1$

12. Food and Agriculture Organization of the United Nations. H7N9 situation update. 2019. Available online: http:// www.fao.org/ag/againfo/programmes/en/empres/H7N9/ situation_update.html

13. World Health Organization. Summary of probable SARS cases with onset of illness from 1 November 2002 to 31 July 2003. Available online: https://www.who.int/csr/sars/ country/table2004_04_21/en/

14. Chan LH, Chen L, Xu J. China's engagement with global health diplomacy: was SARS a watershed? PLoS Med 2010;7:e1000266.

15. Sun $M, X u$ N, Li C, et al. The public health emergency management system in China: trends from 2002 to 2012. BMC Public Health 2018;18:474.

16. Zhong N, Zeng G. What we have learnt from SARS epidemics in China. BMJ 2006;333:389-91.

17. Enserink M. SARS in China. China's missed chance. Science 2003;301:294-6.

18. National Health Commission of the People's Republic of China. Administrative measures for the prevention and control of infectious atypical pneumonia (order of the Ministry of Health No. 35). 2003. Available online: http:// www.nhc.gov.cn/wjw/bmgz/200804/111f50e92a1d45a68e0 4b32c352b9484.shtml

19. National Health Commission of the People's Republic of China. Ministry of Health says "four early" measures to fight SARS. 2003. Available online: http://www.nhc.gov. cn/wjw/zcjd/201304/265b2e17388d48d0b87f8480f69cf 1c3.shtml

20. Xu RH, He JF, Evans MR, et al. Epidemiologic clues to SARS origin in China. Emerg Infect Dis 2004;10:1030-7.

21. National Health Commission of the People's Republic of China. National Implementation Plan for Surveillance of Unexplained Pneumonia (Trial). 2004. Available online: http://www.nhc.gov.cn/wjw/zcjd/201304/ad9b232676bb46 71a20b6fbdd26c1376.shtml

22. The Central Committee of the Communist Party of China and the State Council of China. National Health Commission and relevant departments jointly prevent and control the pneumonia epidemic of new coronavirus infection. 2020. Available online: http://www.gov.cn/ xinwen/2020-01/22/content_5471437.htm
23. Kickbusch I, Leung G. Response to the emerging novel coronavirus outbreak. BMJ 2020;368:m406.

24. National Health Commission of the People's Republic of China. New coronavirus pneumonia prevention and control program (second edition). 2020. Available online: http://www.nhc.gov.cn/jkj/s3577/202001/c67cfe29ecf1470 e8c7fc47d3b751e88.shtml

25. Press conference of the State Council's Joint Prevention and Control Mechanism: Introduce the work of centralized admission and treatment in the shelter hospital. Available online: http://www.gov.cn/xinwen/gwylflkjz123/index.htm

26. The Central Committee of the Communist Party of China and the State Council of China. National Health Commission: Coordinated arrangements for 19 provincial counterparts to support 16 cities and counties in Hubei except Wuhan. 2020. Available online: http://www.gov.cn/ xinwen/2020-02/11/content_5477116.htm

27. Ministry of National Defense of the People's Republic of China. Nearly 3,000 beds have been set up in the army, and more than 10,000 medical staff have been sent to the front line for treatment. 2020. Available online: http:// www.mod.gov.cn/topnews/2020-03/03/content_4861388. htm

28. Wuhan People's Government. Interim measures for prevention and control of pneumonia of new coronavirus infection in Wuhan. 2020. Available online: http://www. chinanews.com/gn/2020/01-30/9073042.shtml

29. The Central Committee of the Communist Party of China and the State Council of China. Ministry of Culture and Tourism: Notice of the general office of the state council on extending the 2020 Chinese New Year holiday. 2020. Available online: http://www.gov.cn/zhengce/ content/2020-01/27/content_5472352.htm

30. General Office of the Ministry of Culture and Tourism. Urgent notice on preventing and controlling the pneumonia epidemic of new coronavirus infection and suspending the business activities of tourism enterprises. 2020. Available online: http://www.gov.cn/ xinwen/2020-01/26/content_5472279.htm

31. National Health Commission of the People's Republic of China. Coronavirus pneumonia diagnosis and treatment plan (trial implementation of revised fifth edition). 2020. Available online: http://www.nhc.gov.cn/yzygj/ s7653p/202002/d4b895337e19445f8d728fcaf1e3e13a. shtml

32. National Health Commission of the People's Republic of China. Notice of the General Office of the National Health Commission on internet diagnosis and treatment 
consulting services in epidemic prevention and control. 2020. Available online: http://www.nhc.gov.cn/yzygj/ s7653p/202002/ec5e345814e744398c2adef17b657fb8. shtml

33. Ministry of Education of the People's Republic of China. Notice of the Ministry of Education on the postponement of the spring semester of 2020. 2020. Available online: http://www.moe.gov.cn/jyb_xwfb/gzdt_gzdt/ s5987/202001/t20200127_416672.html

34. The Central Committee of the Communist Party of China and the State Council of China. Ministry of Civil Affairs: All national industry associations and chambers of commerce are temporarily not allowed to hold various gathering activities. 2020. Available online: http://www. gov.cn/xinwen/2020-02/06/content_5475377.htm

35. The Central Committee of the Communist Party of China and the State Council of China. Ministry of Culture and Tourism: National travel agency suspends group travel. 2020. Available online: http://www.gov.cn/ xinwen/2020-01/26/content_5472277.htm

36. The Central Committee of the Communist Party of China and the State Council of China. China completely bans illegal wildlife trade. 2020. Available online: http://www. gov.cn/xinwen/2020-02/24/content_5482761.htm

37. National Health Commission of the People's Republic of China. Notice regarding the issuance of guidelines for health protection in shopping malls and supermarkets during the epidemic of the new coronavirus pneumonia. 2020. Available online: http://www.nhc.gov.cn/xcs/zhengc wj/202002/6a13deef74604f39a16390679d98283c.shtml

38. National Health Commission of the People's Republic of China. Urgent notice from the Ministry of Civil Affairs and the National Health Commission on further mobilizing urban and rural community organizations to carry out the prevention and control of pneumonia outbreaks of new coronavirus infection. 2020. Available online: http://www.nhc.gov.cn/xcs/zhengcwj/202001/1d27 e24c56fb47e3bb98d7e39c9ccb17.shtml

39. The Central Committee of the Communist Party of China and the State Council of China. National road passenger transport and city buses resumed operation in an orderly manner. 2020. Available online: http://www.gov.cn/ xinwen/2020-02/13/content_5478150.htm

40. The Central Committee of the Communist Party of China and the State Council of China. Wuhan City, New Coronavirus Pneumonia Prevention and Control Command Notice (No. 1). 2020. Available online: http:// www.gov.cn/xinwen/2020-01/23/content_5471751.htm
41. The Central Committee of the Communist Party of China and the State Council of China. Expansion of Hubei's bed supply will requisition a number of hotel venue training centers. 2020. Available online: http://www.gov.cn/ xinwen/2020-02/05/content_5474706.htm

42. The Central Committee of the Communist Party of China and the State Council of China. Guangdong: Going all out to reduce the risk of spread of epidemic communities. 2020. Available online: http://www.gov.cn/ xinwen/2020-01/30/content_5473033.htm

43. The Central Committee of the Communist Party of China and the State Council of China. Zhejiang: Registration required for fever and cough medicines. 2020. Available online: http://www.gov.cn/xinwen/2020-02/01/ content_5473549.htm

44. The Central Committee of the Communist Party of China and the State Council of China. Beijing Drug Administration: Real-name registration for purchase of fever and cough medicines at pharmacies. 2020. Available online: http://www.gov.cn/xinwen/2020-02/13/ content_5477967.htm

45. General Office of Shenzhen Municipal People's Government. Shenzhen Headquarters for Prevention and Control of Pneumonia Epidemic Caused by Novel Coronavirus Issued Measures to Build and Improve A Joint Prevention and Control Mechanism in Residential Communities. 2020. Available online: http://www.sz.gov. cn/en_szgov/news/latest/content/post_6723982.html

46. The People's Government of Liaoning Province. Notice on Issuing 30 Measures for Strict Investigation and Control of Outbreaks in Urban and Rural Communities (Villages) in the Province. 2020. Available online: http:// www.ln.gov.cn/zfxx/tzgg/202002/t20200205_3734347. html

47. People's Government of Guangdong Province. Guangdong issues strict epidemic prevention notice. 2020. Available online: http://www.gd.gov.cn/gdywdt/zwzt/yqfk/gdzxd/ content/post_2879351.html

48. Information Office of The Shanghai Municipal People's Government. When entering public places, you must consciously wear a mask. 2020. Available online: http:// www.shio.gov.cn/sh/xwb/n782/n783/u1ai23429.html

49. Sohu News. What are the new policies and regulations in Beijing during the epidemic? A must-see for those returning to Beijing! Available online: https://www. sohu.com/a/372376402_391283?_trans_=000014_bdss_ dklzxbpcgP3p:CP=

50. Hainan Provincial People's Government. Notice of 
Hainan Provincial Epidemic Prevention and Control Work Headquarters on Further Improving Recent Epidemic Prevention and Control. 2020. Available online: http://www.hainan.gov.cn/hainan/yxtkfgfczccs/202002/511 3def6b1904d09a4961c6d666fe5cb.shtml

51. The Central Committee of the Communist Party of China and the State Council of China. Medical consultation search tool for coronavirus disease treatment. Available online: http://bmfw.www.gov.cn/xxgzbdfyjycxjkzg/index. html

52. Qiandongnan Prefecture Health and Health Bureau. State Center for Disease Control launches nucleic acid testing training. 2020. Available online: http://wsjsw.qdn.gov.cn/ gzdt/bmdt/202002/t20200203_46923298.html

53. Shijiazhuang Municipal Health Committee. The city organizes training for nucleic acid testing staff at designated county-level hospitals. 2020. Available online: http://wsjk.sjz.gov.cn/html/sjdt/2020-218/20218105249IEC5.html

54. Guangzhou Municipal People's Government. Circular of Guangzhou Headquarters for Prevention and Control of Pneumonia Epidemic Caused by Novel Coronavirus Infections on further strengthening community and rural epidemic prevention and control (No. 3). 2020. Available online: http://www.gz.gov.cn/xw/tzgg/content/ post_5655563.html

55. Foreign Affairs Office of the Shenzhen Municipal People's Government. Shenzhen Headquarters for Prevention and Control of Pneumonia epidemic caused by novel coronavirus issued measures to build and improve a joint prevention and control mechanism in residential communities. 2020. Available online: http://www.sz.gov. cn/en_szgov/news/latest/content/post_6723982.html

56. The Central Committee of the Communist Party of China and the State Council of China. Zhengzhou: Passengers must wear masks when traveling on the subway. 2020. Available online: http://www.gov.cn/xinwen/2020-01/26/ content_5472317.htm\#1

57. China News Network. Wuhan requires the city to wear masks in public places. 2020. Available online: http://www. chinanews.com/m/kong/2020/01-22/9067622.shtml

58. Sohu News. Suspected patients were strictly controlled, and pharmacies nationwide stopped selling fever, cough and cold medicines, but... 2020. Available online: https:// www.sohu.com/a/371784830_734412

59. Chutian Metropolis Daily. Community volunteers help isolate patients to buy medicines, monitor the body temperature at the entrance of the community. 2020.
Available online: https://baijiahao.baidu.com/s?id=165713 $9456401362806 \& w \mathrm{wf}=$ spider $\&$ for $=\mathrm{pc}$

60. The Central Committee of the Communist Party of China and the State Council of China. Notice on Strengthening Community Prevention and Control of Pneumonia Epidemic of New Coronavirus Infection. 2020. Available online: http://www.gov.cn/xinwen/2020-01/27/ content_5472481.htm

61. Center for Strategic \& International Studies. How webconnected is China? 2020. Available online: https:// chinapower.csis.org/web-connectedness/

62. The Central Committee of the Communist Party of China and the State Council of China. Use big data to strengthen accurate measures for epidemic prevention and control. 2020. Available online: http://www.gov.cn/ xinwen/2020-01/27/content_5472436.htm

63. State Administration of Science Technology and Industry for National Defence of the People's Republic of China. The close contact meter of COVID-19 patients has been launched. 2020. Available online: http://www.sastind.gov. cn/n112/n117/c6808819/content.html

64. Ministry of Industry and Information Technology of The People's Republic of China. Ministry of Industry and Information Technology introduction of the overall situation of telecommunication big data analysis for the prevention and control of COVID-19. 2020. Available online: http://www.miit.gov.cn/n973401/n7647394/ n7647404/c7678465/content.html

65. Xinhuanet. Tencent takes the lead in drafting the first "epidemic prevention travel code" group standard to help prevent and control epidemics and resume production. 2020. Available online: http://www.xinhuanet.com/ tech/2020-03/06/c_1125674248.htm

66. The Central Committee of the Communist Party of China and the State Council of China. Wuhan announces interim measures for prevention and control of pneumonia outbreak of new coronavirus infection. 2020. Available online: http://www.gov.cn/xinwen/2020-01/30/ content_5473071.htm

67. Sina News. Guangdong People's Hospital enables 5G infrared temperature measurement with accuracy to \pm 0.2 degrees Celsius. 2020. Available online: http://news.sina. com.cn/s/2020-02-06/doc-iimxxste9254472.shtml

68. Zhejiang Municipial People's Government. The nation's first $5 \mathrm{G}$ medical temperature patrol robot came to work in Zhejiang Province. 2020. Available online: http://www. hangzhou.gov.cn/art/2020/2/7/art_812262_41886452. html 
69. China Daily. Guangxi's first 5G thermal imaging temperature measuring device put into use in Qinzhou. 2020. Available online: http://ex.chinadaily.com.cn/ exchange/partners/82/rss/channel/cn/columns/80x78w/ stories/WS5e3d0e93a3107bb6b579dd2b.html

70. Publicity Department of the Wuhan Municipal Committee. Single-day sample detection capacity increased from initial 200 to thousands. 2020. Available online: http://www.whxc.org.cn/2020/0207/60079.shtml

71. Wuhan Municipal Health Commission. Epidemic Situation of New Coronavirus Pneumonia in Hubei Province on February 12, 2020. 2020. Available online: http://www.cjrbapp.cjn.cn/p/159802.html

72. National Health Commission of the People's Republic of China. Transcript of the press conference on February 4, 2020. 2020. Available online: http://www.nhc.gov.cn/xcs/fk $\mathrm{dt} / 202002 / 35990 \mathrm{~d} 56 \mathrm{cfcb} 43 \mathrm{f} 4 \mathrm{a} 70 \mathrm{~d} 7 \mathrm{f} 9703 \mathrm{~b} 113 \mathrm{c} 0$.shtml

73. Guan WJ, Ni ZY, Hu Y, et al. Clinical characteristics of coronavirus disease 2019 in China. N Engl J Med 2020;382:1708-20.

74. Lan L, Xu D, Ye G, et al. Positive RT-PCR test results in patients recovered from COVID-19. JAMA 2020;323:1502-3.

75. Southern Metropolis Daily. Why does the patient have Fuyang? One paper reveals 6 reasons. 2020. Available online: https://mp.weixin.qq.com/s?biz=MTk1MjIwOD AwMQ==\&mid=2650846273\&idx=2\&sn=70245984f97 $8 \mathrm{a} 5 \mathrm{~b} 5 \mathrm{c} 3 \mathrm{a} 493 \mathrm{faa} 193 \mathrm{da} 3 \mathrm{f} \& \mathrm{chksm}=4797 \mathrm{~b} 7 \mathrm{af} 70 \mathrm{e} 03 \mathrm{eb} 9 \mathrm{ce} 7$ 564a94cee89a90e1f051150e58faa4956457f4c7134428ee a1a3e210d \&mpshare $=1 \&$ scene $=1 \&$ srcid $=\&$ sharer sharetime $=1583998601874 \&$ sharer_shareid $=\mathrm{f} 470 \mathrm{a} 0 \mathrm{~b} 42 \mathrm{dc}$ 23d3570d905791fb29fd2\&exportkey=AsQ1xjQGk9wmH wkUmpHmNLA\%3D\&pass_ticket=Q7olysXh0IAAuiwtK \%2BtGfB1V3ketUba2w5yHX0uPfIA\%3D\#rd

76. Xu K, Cai H, Shen Y, et al. Management of corona virus disease-19 (COVID-19): the Zhejiang experience. Zhejiang Da Xue Xue Bao Yi Xue Ban 2020;49:0.

77. Tang A, Tong ZD, Wang HL, et al. Detection of novel coronavirus by RT-PCR in stool specimen from asymptomatic child, China. Emerg Infect Dis 2020;26:1337-9.

78. General Office of the People's Government of Hubei Province. Hubei Provincial New Coronavirus Infection Prevention and Control Headquarters Notice. 2020. Available online: http://www.hubei.gov.cn/zhuanti/2020/ gzxxgzbd/zxtb/202003/t20200324_2189256.shtml

79. Shanghai Municipal Health Commission. Shanghai decides to adjust the primary public health emergency response to a secondary response. 2020. Available online: http://wsjkw.sh.gov.cn/xwfb/20200323/3219ce0f5c1c4f7ba 2af713340ab2b03.html

80. Guangdong Provincial Health Committee. Guangdong Province decides to adjust the primary response of major public health emergencies to secondary response. 2020. Available online: http://wsjkw.gd.gov.cn/gkmlpt/ content/2/2905/post_2905977.html\#2571

81. The Central Committee of the Communist Party of China and the State Council of China. Steady and orderly resumption of work and production across the country. 2020. Available online: http://www.gov.cn/ xinwen/2020-02/11/content_5477083.htm

82. Sohu News. List of major cities' anti-epidemic measures against inbound tourists. 2020. Available online:: https:// www.sohu.com/a/380902981_489610

83. Civil Aviation Administration of China. Notice on continuing to reduce the number of international passenger flights during the epidemic prevention and control. 2020. Available online: http://www.caac.gov.cn/ XXGK/XXGK/TZTG/202003/t20200326_201746.html

84. Ministry of Foreign Affairs of the People's Republic of China. Ministry of Foreign Affairs of the People's Republic of China National Immigration Administration Announcement on the Temporary Suspension of Entry by Foreign Nationals Holding Valid Chinese Visas or Residence Permits. 2020. Available online: https://www. fmprc.gov.cn/mfa_eng/wjbxw/t1761867.shtml?from=grou pmessage\&isappinstalled $=0$

85. China Network. How will Wuhan continue to prevent and control the epidemic after it is unblocked? Available online: http://news.china.com.cn/txt/2020-04/09/ content_75911387.htm

86. Yu F, Du L, Ojcius DM, et al. Measures for diagnosing and treating infections by a novel coronavirus responsible for a pneumonia outbreak originating in Wuhan, China. Microbes Infect 2020;22:74-9.

87. Sheng L. The impact of the epidemic will not change the long-term trend of China's economy. 2020. Available online: http://paper.people.com.cn/rmrb/html/202003/23/nw.D110000renmrb_20200323_1-18.htm

Cite this article as: Zanin M, Xiao C, Liang T, Ling S, Zhao F, Huang Z, Lin F, Lin X, Jiang Z, Wong SS. The public health response to the COVID-19 outbreak in mainland China: a narrative review. J Thorac Dis 2020;12(8):4434-4449. doi: $10.21037 /$ jtd-20-2363 
A detailed summary of events and responses in Hubei Province is provided as an additional supplement.

\section{Timeline of events in Wuhan and Hubei $\underline{2019}$}

\section{December 31}

Announcement of a cluster of pneumonia of unknown etiology (PUE) cases associated with the Huanan (South China) Seafood Market.

\section{$\underline{2020}$}

\section{January 1}

Huanan Market was closed and sanitized.

\section{January 12}

All confirmed cases of COVID-19 were transferred to Wuhan Jinyintan Hospital for centralized treatment.

\section{January 14}

Commencement of body temperature measurements on passengers departing from Wuhan airports and train stations.

\section{January 20}

270 cases in Hubei, 1,070 close contacts were tracked, 739 people released from medical observation, and 331 people still receiving medical observation.

The State Council approved the inclusion of the novel coronavirus pneumonia as a Class B infectious disease and adopted measures to prevent and control Class $\mathrm{A}$ infectious diseases. The Wuhan Municipal Health Commission announced the list of fever clinics and designated medical institutions in the city; 61 fever clinics in Wuhan, including 41 in the central city area, and 20 in the new city area, and 16 city management hospitals. Nine designated medical institutions were established in the city. Among them in the central urban area were Wuhan Jinyintan Hospital, Wuhan Pulmonary Hospital, and Wuhan Hankou Hospital.

\section{January 21}

375 cases in Hubei, 1,181 close contacts tracked, 755 people released from medical observation, and 426 people still receiving medical observation.

\section{January 22}

444 cases in Hubei, 2,556 close contacts tracked, 863 people released from medical observation, and 1,693 people still receiving medical observation.

The Hubei Provincial Government initiated a level II emergency response to a public health emergency.

\section{January 23}

549 cases in Hubei, 3,653 close contacts tracked, 877 people released from medical observation, and 2,776 people still receiving medical observation.
Travel agencies in the province suspended business activities. Colleges, primary schools, and kindergartens in Hubei Province delayed opening. Passenger flights, passenger trains, passenger cars, and passenger ships in and out of Wuhan in Hubei Province temporarily suspended. Wuhan locked down.

\section{January 24}

729 cases in Hubei, 5,682 close contacts tracked, 971 released from medical observation, and 4,711 still receiving medical observation.

Hubei Province initiated a Grade I response to a major public health emergency. Wuhan implements a classified medical treatment system. Each community was deemed responsible for comprehensively examining fever patients in its jurisdiction, and sending them to the community medical and health service center for screening.

\section{January 25}

1,052 cases in Hubei, 7,989 close contacts tracked, 1,085 released from medical observations, and 6,904 people still receiving medical observation.

Approximately 450 people from the Air Force Military Medical University (Xi'an), Army Military Medical University (Chongqing), Naval Military Medical University (Shanghai), three military medical university-affiliated hospitals, and a number of Guangzhou medical rescue teams were sent to Wuhan.

\section{February 2}

11,177 cases in Hubei, 56,088 close contacts tracked, and 48,171 still receiving medical observation.

The Municipal Health and Medical Commission requisitioned 27 additional medical institutions as designated hospitals, for a total of 54 designated hospitals in the city, including the newly-built Vulcan Mountain Hospital and Thunder Mountain Hospital.

\section{February 3}

13,522 cases in Hubei, 68,988 close contacts tracked, and 58,544 people still receiving medical observation.

The health and market management departments of various districts of Wuhan conducted daily air and surface monitoring in more than 240 medical institutions, more than 30 centralized isolation places, and more than 260 market fairs in the city. The urban management departments of various districts in Wuhan used artillery fog trucks, sprinkler trucks as well as manual disinfection to provide daily sanitation service to more than 240 medical institutions, 400 markets, more than 2,000 personal trafficintensive neighborhoods, and more than 80,000 garbage containers, 220 waste stations, 14 garbage processing plants, 
and more than 1,700 public toilets. More than 15,000 liters of disinfectant were used to sanitize more than five million square meters. The urban management department of Wuhan masks, personal protective equipment, disinfectants, and hand sanitizers through multiple channels.

Wuhan's new coronavirus-infected pneumonia epidemic prevention and control headquarters has opened an "online consultation" platform. As of 22:00 on February 5th, 11 hours after the invitation was issued, 309 doctors from more than 120 departments in 247 medical institutions across China participated to provide online medical advice.

\section{February 5}

19,665 cases in Hubei, 90,997 close contacts tracked, and 64,127 people still receiving medical observation.

Since 23:00 on February 5th, the first three square cabin hospitals, a type of mobile medical system of the People's Liberation Army, were opened in Wuhan for COVID-19 patients with mild illness (i.e., low fever, mild fatigue and no pneumonia on imaging).

\section{February 6}

22,112 cases in Hubei, 101,599 close contacts tracked, and 64,057 still receiving medical observation.

Hubei Provincial Health and Health Committee assigned medical treatment to designated hospitals for special populations such as pregnant women, children, and hemodialysis patients suspected or diagnosed with the new type of coronavirus. The Wuhan "Fire Eye" biosafety laboratory in the Donghu High-tech Zone was established, which could process up to 10,000 samples per day. Wuhan adopted an artificial intelligence and manual mapping platform to carry out national body temperature monitoring.

February 8

27,013 cases in Hubei, 123,827 close contacts tracked, and 70,438 people still receiving medical observation.

Thunder Mountain Hospital was officially delivered to Zhongnan Hospital of Wuhan University and the first patients were admitted. The hospital has 32 wards and 1,600 beds, built based on the model of the rapidly established Xiaotangshan Hospital in Beijing during the 2003 SARS outbreak. Wuhan has initiated return arrangements for Wuhan residents stranded outside Hubei Province. Due to increased demand, the new campus of the Hubei Provincial Party School and four universities in Wuhan were temporarily requisitioned and transformed into designated medical sites, adding a total of 5,400 beds.

\section{February 12}

48,206 cases in Hubei, 158,377 close contacts tracked, and 77,308 people still receiving medical observation.

Hubei Province announced the addition of suspected and confirmed cases to the total case tally of clinically diagnosed cases. If the suspected case has the imaging characteristics of pneumonia, it was classified as a clinically diagnosed case.

\section{February 13}

51,986 cases in Hubei, 166,818 close contacts tracked, and 77,685 people still receiving medical observation.

Individuals recovered from COVID-19 were called upon to donate plasma to help critically ill patients.

\section{March 1}

67,103 cases in Hubei, 267,585 close contacts tracked, and 32,143 people still receiving medical observation.

\section{March 12}

67,786 cases in Hubei, 274,992 close contacts tracked, and 6,810 people still receiving medical observation.

More than 346 medical teams and 42,600 medical staff have been sent to Hubei. This doubled the medical care capacity that was available in the province. Nineteen provinces across the country supported 16 cities and prefectures in Hubei Province. Hubei Province designated a total of 238 designated treatment hospitals and 16 square cabin hospitals.

\section{March 14}

No new suspected cases in Hubei Province. 